\title{
Effect of gastrectomy on the pharmacokinetics of S-1, an oral fluoropyrimidine, in resectable gastric cancer patients
}

\author{
Mitsugu Kochi • Masashi Fujii • Noriaki Kanamori • \\ Teruo Kaiga • Kazuo Aizaki • Toru Takahashi • \\ Tadatoshi Takayama
}

Received: 20 September 2006 / Accepted: 29 December 2006 / Published online: 15 February 2007

(C) Springer-Verlag 2007

\begin{abstract}
Purpose The effect of gastrectomy on pharmacokinetics after S-1 administration was investigated.

Patients and methods A dose of $40 \mathrm{mg} / \mathrm{m}^{2}$ of S-1 was administered orally twice daily for 7 days $\left(80 \mathrm{mg} / \mathrm{m}^{2} /\right.$ day) preoperatively in ten patients with resectable gastric cancer, and the same dose of S- 1 was administered for 28 consecutive days after gastrectomy. Plasma concentrations of tegafur, gimeracil, and oteracil potassium, all the components of S-1, and 5-FU were measured on pre- and postoperative days. Concentrations of 5-FU in tumor and normal tissues were also determined.

Results At day 4 from the initial preoperative administration of S-1, the AUC of 5-FU was 1,055 $\pm 304 \mathrm{ng} \mathrm{h} /$ $\mathrm{ml}$. At day 18, day 28, and day 42 after gastrectomy, it was $1,012 \pm 331,1,070 \pm 403$, and $946 \pm 226 \mathrm{ng} \mathrm{h} / \mathrm{ml}$, respectively. No significant differences for plasma 5-FU were observed between pre- and postoperative days. In the resected tumor tissues, concentrations of 5-FU were $242 \pm 83 \mathrm{ng} / \mathrm{g}$ around $4.5 \mathrm{~h}$ and $91.7 \pm 37.0 \mathrm{ng} / \mathrm{g}$ around $20 \mathrm{~h}$ after the final administration, respectively.

Conclusion Gastrectomy does not affect on pharmacokinetics of 5-FU derived from S-1 regardless of partial or total gastrectomy, indicating that $\mathrm{S}-1$ can be a useful drug in postoperative adjuvant chemotherapy for gastric cancer.
\end{abstract}

\footnotetext{
M. Kochi $(\bowtie) \cdot$ M. Fujii $\cdot$ N. Kanamori $\cdot$ T. Kaiga ·

K. Aizaki $\cdot$ T. Takahashi $\cdot$ T. Takayama

Department of Digestive Surgery,

Nihon University School of Medicine,

30-1, Ohyaguchi Kamimachi, Itabashi-ku,

Tokyo 173-8610, Japan

e-mail: gann@med.nihon-u.ac.jp
}

Keywords Gastrectomy $\cdot$ Pharmacokinetics $\cdot$ S- 1 . Oral fluoropyrimidine

\section{Introduction}

S-1 (TS- $\left.1^{\circledR}\right)$ is an oral anticancer drug containing tegafur (FT), a prodrug of fluorouracil (5-FU) combined with two modulators, 5-chloro-2,4-dihydroxypyridine (gimeracil, CDHP) and oteracil potassium (Oxo), in a molar ratio of 1:0.4:1 [10]. CDHP competitively inhibits dihydropyrimidine dehydrogenase (DPD), a key enzyme of 5-FU degradation, in a reversible manner, to maintain high 5-FU concentrations in plasma and tumors over a long period of time. Oxo is distributed in the gastrointestinal tract at high concentrations after oral administration and inhibits phosphorylation of 5-FU in the gastrointestinal tract to enable a reduction in gastrointestinal toxicity $[3,6,10,17]$. The response rates were $53.6 \%(15 / 28)$ in an early phase II study in patients with advanced gastric cancer including previously treated patients [12]. The response rate of two pivotal late phase II studies was $49 \%(25 / 51)$ and $40 \%(20 / 50)$, respectively [5, 9]. This drug exhibits high efficacy against advanced gastric cancer and can be administered at outpatient clinics. Its use in postoperative adjuvant chemotherapy is thus anticipated as a means of improving patients' quality of life (QOL). At present, however, no clinical results have been obtained concerning its use in postoperative adjuvant chemotherapy. When the use of S- 1 as postoperative adjuvant chemotherapy is considered, a study of the effects of gastrectomy on pharmacokinetics promises to provide important findings to determine the daily dose as well as the dosing schedule for S-1, because all the components of S-1 are absorbed in the small intestine. 
The primary objective of this study was to show whether gastrectomy affects the pharmacokinetics of $\mathrm{S}-1$. We also determined tissue concentrations of FU following preoperative administration of $\mathrm{S}-1$ as a secondary objective.

\section{Materials and methods}

This study was performed according to the guidelines of the Declaration of Helsinki as amended in Edinburgh, Scotland, October 2000, and the protocol was approved by the Institutional Review Board of Nihon University School of Medicine.

\section{Patients}

Patients enrolled prospectively in the study were required to meet the following criteria: (1) histologically proven, resectable gastric cancer; (2) aged 20-74 years old; (3) Eastern Cooperative Oncology Group performance status (PS) $0-2$; (4) adequate organ functions defined as a leukocyte count of 4,000-12,000, platelet count $\geq 100,000$, serum transaminase (aspartate aminotransferase and alanine aminotransferase) levels $\leq 100 \mathrm{U}$, serum bilirubin level $\leq 1.5 \mathrm{mg} / \mathrm{dl}$, and serum creatinine $\leq$ upper limit of the normal range; (5) no prior chemotherapy or radiotherapy; (6) no other severe medical conditions; and (7) provision of written informed consent by the patients.

\section{Gastric surgery}

All patients who were enrolled into this study underwent curative resection with partial gastrectomy with Billroth I reconstruction or total gastrectomy with Roux-en-Y reconstruction according to preoperative diagnosis.

\section{Study plan}

S-1 was administered for seven consecutive days before surgery. The dosage was determined according to body surface area (BSA); the Japanese standard dose was $80 \mathrm{mg} / \mathrm{m}^{2} /$ day, with $40 \mathrm{mg} / \mathrm{m}^{2} /$ dose. The drug was administered twice daily, within $30 \mathrm{~min}$ after breakfast and dinner, at a dose of $40 \mathrm{mg}$ ( $20 \mathrm{mg} \times 2$ capsules) for BSA $<1.25 \mathrm{~m}^{2}, 50 \mathrm{mg}(25 \mathrm{mg} \times 2$ capsules $)$ for $1.25 \mathrm{~m}^{2}$ $\leq \mathrm{BSA}<1.50 \mathrm{~m}^{2}$, and $60 \mathrm{mg}$ (20 mg $\times 3$ capsules $)$ for BSA $>1.50 \mathrm{~m}^{2}$. The drugs were administered between 8:00 and 9:00 in the morning and between 5:30 and 7:00 in the evening.

Among patients for whom 5-FU concentration in a tumor was measured, for those receiving S-1 up to and including the day of surgery, S-1 was administered at $40 \mathrm{mg} / \mathrm{m}^{2}$ under fasting conditions once before surgery in the morning of the day of surgery. For patients receiving S-1 up to the evening before surgery, the final administration of S-1 was conducted the night before surgery. Postoperative administration of S-1 was conducted orally for 28 consecutive days beginning on day 15 (from day 15 to day 42) after the day of surgery. The daily dose and times of administration of S-1 were the same as those in the preoperative S-1 administration schedule.

\section{Sample collection}

Blood samples were collected on a total of 4 days, once before surgery, in the morning on day -4 from the day of surgery (on day 4 after starting preoperative administration of S-1), and 3 days after surgery, in the morning on days 18,28 , and 42 after the day of surgery (on days 4,14 , and 28 after starting postoperative administration of S-1). Blood samples were collected at six points on each day, before administration and 1, 2, 4, 6, and $8 \mathrm{~h}$ after the administration of S-1. Peripheral blood samples were collected into a heparinized tube at a volume of $8 \mathrm{ml}$ at each sampling time and centrifuged at $3,000 \mathrm{rpm}$ for $15 \mathrm{~min}$ at $4^{\circ} \mathrm{C}$; the plasma was stored at $-20^{\circ} \mathrm{C}$. During surgery, a tissue sample (minimum $1 \mathrm{~g}$ ) of the primary tumor and a normal tissue sample (minimum $1 \mathrm{~g}$ ) were removed together with a blood sample $(1-2 \mathrm{ml})$. The samples were cleansed of fat and other debris, quickly frozen, and stored at $-70^{\circ} \mathrm{C}$.

\section{Drug assay}

Analysis of FT, 5-FU, CDHP, and Oxo was conducted according to the method of Matsushima et al. [8]. In brief, FT was extracted with dichloromethane from each sample and analyzed using HPLC equipped with a UV absorption spectrometer. 5-FU and CDHP were extracted with ethyl acetate from the residue obtained after dichloromethane extraction, and pentafluorobenzyl derivatives were prepared. 5-FU and CDHP were analyzed using a negative ion chemical ionization-gas chromatograph/mass spectrometer (NICI-GC/MS). Oxo was extracted separately from the samples using a solid extraction column, then decarbonated, prepared in a pentafluorobenzyl derivative, and assayed using NICI-GC/MS. For the analysis of CDHP, 5-FU, and Oxo by GC/MS, a stable isotope for each compound was used as an internal reference. The lower limit of quantification (LLOQ) of FT, 5-FU, CDHP, and Oxo in plasma were $10,1,2$, and $1 \mathrm{ng} / \mathrm{ml}$, respectively. 
Normal and tumor tissues were homogenized in saline with a POLYTRON homogenizer (KINEMATICA Inc., NJ, USA). The homogenate was then centrifuged at $1,000 \times \mathrm{g}$ for $15 \mathrm{~min}$ at $4^{\circ} \mathrm{C}$. The supernatant was used for determination of 5-FU by the abovementioned method.

\section{PK parameters}

The plasma concentration-time data after administration of S-1 were analyzed by the noncompartmental method using a WinNonlin computer program (version 3.1; Pharsight Co, Apex, NC, USA). The peak plasma concentration $\left(C_{\max }\right)$ and the time to reach the peak concentration $\left(T_{\max }\right)$ were recorded directly from experimental observations. The area under the plasma concentration-time curve (AUC) from time 0 up to $8 \mathrm{~h}$ after administration, $\mathrm{AUC}_{0-8 \mathrm{~h}}$, was calculated by the linear trapezoidal method. No weighting factor was used, and the slope of the terminal phase of the plasma profile, $K$, was determined by log-linear regression of at least three data points, which yielded a minimum mean square error. The absolute value of $K$ was used to estimate the terminal half-life $\left(t_{1 / 2}\right)$ according to the formula $t_{1 / 2}=\ln 2 / K$. Since no terminal log-linear phase was identified in a minority of the patients, the $t_{1 / 2}$ values in these patients could not be calculated.

\section{Statistical analysis}

Values were expressed as means \pm standard deviations. As a primary analysis, the effect of gastrectomy was tested by an analysis of variance (ANOVA) using the PK parameters after natural-log transformation. ANOVA was employed with gastrectomy as a fixed effect and patients as random effect. Intra-patient variability was considered in the analysis with the covariance structure of compound symmetry. All the data of patients including unbalanced data were used for the analysis. As a secondary analysis, a Student's paired $t$ test was employed to test the change in PK parameters of FT, 5-FU, CDHP, and Oxo on days 18, 28 , and 42 after the day of surgery comparing with the data on day 4 (day -4 from the day of surgery) after preoperative S-1 administration. The data were stratified into two subgroups of patients with partial and total gastrectomy, and then the data of subgroups were exploratory analyzed with the same procedure. SAS for Windows release 8.02 (SAS Institute Inc., USA) and Microsoft Excel 2003 (Microsoft Co., Ltd., Japan) were used for the statistical analysis and the data calculation.

\section{Results}

\section{Patients characteristics}

Ten patients who satisfied the eligibility criteria for this study were included in the analysis. These patients consisted of nine men and one woman, with the median age of 66 years (range 59-72 years). All patients underwent curative resection, with five patients undergoing partial gastrectomy with Billroth I reconstruction and five patients undergoing total gastrectomy with Roux-en-Y reconstruction, respectively.

\section{S-1 administration}

The median body surface area of these ten patients was $1.40 \mathrm{~m}^{2}$ (range $1.24-1.86 \mathrm{~m}^{2}$ ). The dose of $\mathrm{S}-1$ was $80 \mathrm{mg} /$ body/day ( $40 \mathrm{mg} /$ body/dose twice per day) for one patient, $100 \mathrm{mg} /$ body/day $(50 \mathrm{mg} /$ body/dose twice per day) for five patients, and $120 \mathrm{mg} /$ body/day $(60 \mathrm{mg} /$ body/dose twice per day) for four patients. Preoperative S-1 administration for 7 days was conducted in all ten patients as planned. Postoperative S-1 administration was discontinued in one patient due to development of stomatitis and diarrhea on day 16 after surgery. A blood sample could not be collected from one patient due to anorexia on day 28 after surgery. Both of these patients had undergone partial gastrectomy.

Pharmacokinetics of FT, 5-FU, CDHP, and Oxo after S-1 administration

The mean plasma concentration of FT, 5-FU, CDHP, and Oxo on day 4 after the start of preoperative S-1 administration (day -4 from the day of surgery) (Pre) and on postoperative days 18 (Post 1), 28 (Post 2), and 42 (Post 3) are shown in Fig. 1. Individual plasma concentration-time profiles of 5-FU on the four periods are shown in Fig. 2.

The PK parameters for FT, 5-FU, CDHP, and Oxo at each period after administration of $\mathrm{S}-1$ are shown in Table 1. The $\mathrm{AUC}_{0-8 \mathrm{~h}}$ and $C_{\max }$ values for FT after surgery were significantly higher than that before surgery, and the increment tended to be larger on days 28 and 42 after surgery. The effect of gastrectomy on $C_{\max }$ of Oxo was not significant, but that tended to decrease on day 18 after surgery. The $t_{1 / 2}$ values of Oxo after surgery were significantly prolonged compared to that before surgery. No significant effect of gastrectomy was found for 5-FU or CDHP on any of the measurement days after surgery. Also, no significant change for $T_{\max }$ values were observed. 

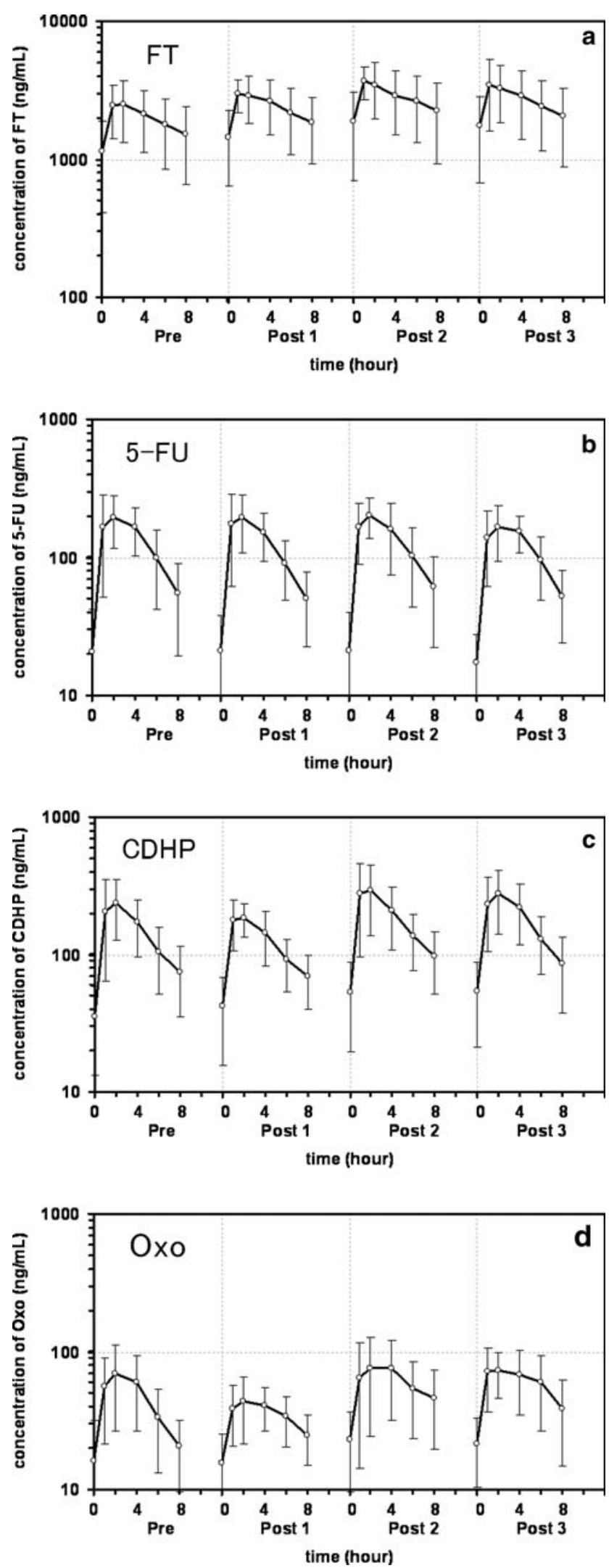

Fig. 1 Changes of plasma FT (a), 5-FU (b), CDHP (c), and Oxo (d) after the start of preoperative S-1 administration (Pre) and on days 18 (Post 1), 28 (Post 2), and 42 (Post 3) after surgery

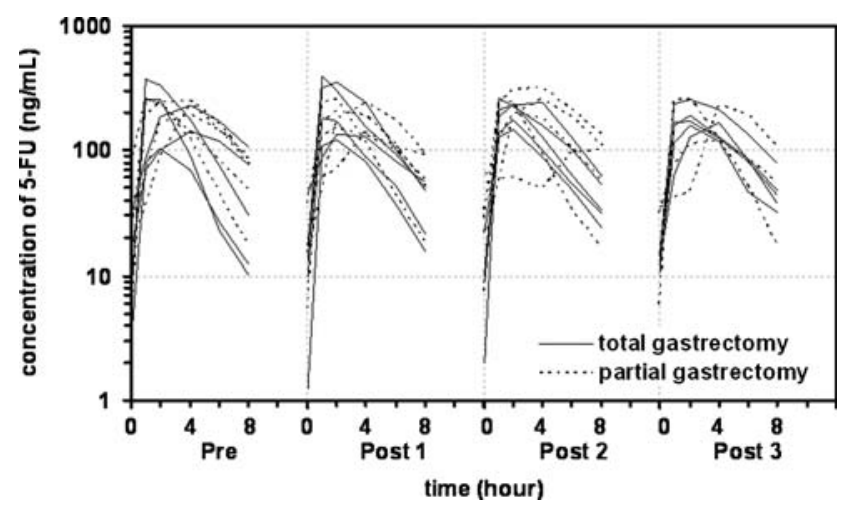

Fig. 2 Individual concentration-time profiles of 5-FU on day 4 after the start of preoperative S-1 administration (Pre) and on postoperative days 18 (Post 1), 28 (Post 2), and 42 (Post 3) after surgery

Influence of gastrectomy

The PK parameters for FT, 5-FU, CDHP, and Oxo at the respective points in time after surgery in five patients undergoing partial gastrectomy with Billroth I reconstruction are shown in Table 2. The PK parameters of five patients undergoing total gastrectomy with Roux-en-Y reconstruction are shown in Table 3. Although the data sizes were limited in these subgroups, no significant effect of gastrectomy was found in patients with partial gastrectomy, however, significant changes were observed in patients with total gastrectomy as similarly to that found in the overall analysis. The effect of gastrectomy on PK of S-1 tended to be apparent in patients with total gastrectomy.

Concentrations of 5-FU in tumor tissues, normal tissues, and plasma

For the four patients who received the final administration of S-1 in the morning of the day of surgery (time from the final administration of S-1 to collection of tissues: median $=4 \mathrm{~h} 35 \mathrm{~min}$, range $=4 \mathrm{~h} 11 \mathrm{~min}$ to $4 \mathrm{~h}$ $54 \mathrm{~min}$ ), the 5-FU concentrations in the tumor tissue was $242 \pm 83 \mathrm{ng} / \mathrm{g}$, the 5 -FU concentration in the normal tissue was $119 \pm 65 \mathrm{ng} / \mathrm{g}$, and the FU concentration in the blood was $90.1 \pm 46.8 \mathrm{ng} / \mathrm{ml}$, with a mean ratio of tumor/ normal tissue of 2.70. In the six patients who received the final administration of S- 1 in the night on the day before surgery (time from the final administration of S- 1 to collection of tissue: median $=19 \mathrm{~h} 45 \mathrm{~min}$, range $=16 \mathrm{~h}$ $45 \mathrm{~min}$ to $22 \mathrm{~h} 45 \mathrm{~min}$ ), the 5 -FU concentration in the tumor tissue was $91.7 \pm 37.0 \mathrm{ng} / \mathrm{g}$, the 5 -FU concentration in the normal tissue was $37.2 \pm 24.4 \mathrm{ng} / \mathrm{g}$, and the 5 FU concentration in the blood was $8.53 \pm 10.24 \mathrm{ng} / \mathrm{ml}$, with a mean ratio of tumor/normal tissue of 8.55 . 
Table 1 PK parameters after administration of S-1 for all cases $(n=10)$ a Paired $t$ test, $P<0.05$ versus Pre

${ }^{b}$ If missing data exist, the number of patients was shown in parenthesis

Table 2 PK parameters after administration of S-1 for partial gastrectomy cases $(n=5)$
${ }^{\text {a }}$ If missing data exist, the number of patients was shown in parenthesis

\begin{tabular}{|c|c|c|c|c|c|c|}
\hline & Assay point & No. of pts & $C_{\max }(\mathrm{ng} / \mathrm{ml})$ & $T_{\max }(\mathrm{h})$ & $\operatorname{AUC}_{0-8 \mathrm{~h}}(\mathrm{ng} \mathrm{h} / \mathrm{ml})$ & $t_{1 / 2}^{\mathrm{b}}(\mathrm{h})$ \\
\hline & $\begin{array}{l}\text { Pre } \\
\text { Post } 1 \\
\text { Post } 2 \\
\text { Post } 3 \\
\text { ANOVA }\end{array}$ & $\begin{array}{l}10 \\
10 \\
10 \\
8 \\
P \text { value } \\
\text { Significance }\end{array}$ & $\begin{array}{l}2,762 \pm 1,097 \\
3,247 \pm 936 \\
3,979 \pm 1,316^{\mathrm{a}} \\
3,784 \pm 1,657^{\mathrm{a}} \\
0.0016 \\
P<0.05\end{array}$ & $\begin{array}{l}1.7 \pm 0.9 \\
1.8 \pm 1.2 \\
1.8 \pm 2.2 \\
1.8 \pm 1.0 \\
0.8585 \\
\text { NS }\end{array}$ & $\begin{array}{l}16,117 \pm 7,590 \\
19,487 \pm 7,753^{\mathrm{a}} \\
23,085 \pm 10,094^{\mathrm{a}} \\
21,854 \pm 10,764^{\mathrm{a}} \\
0.0008 \\
P<0.05\end{array}$ & $\begin{array}{l}9.03 \pm 4.62 \\
8.43 \pm 4.86 \\
7.66 \pm 1.81(9) \\
7.69 \pm 2.59 \\
0.7979 \\
\text { NS }\end{array}$ \\
\hline $5-\mathrm{FU}$ & $\begin{array}{l}\text { Pre } \\
\text { Post } 1 \\
\text { Post } 2 \\
\text { Post } 3 \\
\text { ANOVA }\end{array}$ & $\begin{array}{l}10 \\
10 \\
10 \\
8 \\
P \text { value } \\
\text { Significance }\end{array}$ & $\begin{array}{l}231 \pm 73 \\
218 \pm 94 \\
219 \pm 63 \\
194 \pm 50 \\
0.3481 \\
\text { NS }\end{array}$ & $\begin{array}{l}2.6 \pm 1.5 \\
2.2 \pm 1.0 \\
3.0 \pm 2.1 \\
2.8 \pm 1.0 \\
0.5363 \\
\text { NS }\end{array}$ & $\begin{array}{l}1,055 \pm 304 \\
1,012 \pm 331 \\
1,070 \pm 403 \\
946 \pm 226 \\
0.5776 \\
\text { NS }\end{array}$ & $\begin{array}{l}2.47 \pm 1.01 \\
2.80 \pm 1.73 \\
2.36 \pm 0.48(9) \\
2.59 \pm 0.73 \\
0.3920 \\
\text { NS }\end{array}$ \\
\hline CDHP & $\begin{array}{l}\text { Pre } \\
\text { Post } 1 \\
\text { Post } 2 \\
\text { Post } 3 \\
\text { ANOVA }\end{array}$ & $\begin{array}{l}10 \\
10 \\
10 \\
8 \\
P \text { value } \\
\text { Significance }\end{array}$ & $\begin{array}{l}297 \pm 120 \\
212 \pm 62 \\
373 \pm 143 \\
335 \pm 107 \\
0.9970 \\
\text { NS }\end{array}$ & $\begin{array}{l}2.2 \pm 1.3 \\
1.9 \pm 1.2 \\
2.4 \pm 2.2 \\
2.3 \pm 1.2 \\
0.9112 \\
\text { NS }\end{array}$ & $\begin{array}{l}1,210 \pm 390 \\
1,018 \pm 228 \\
1,533 \pm 549 \\
1,468 \pm 423 \\
0.5452 \\
\text { NS }\end{array}$ & $\begin{array}{l}3.49 \pm 1.44 \\
4.05 \pm 1.95(9) \\
3.12 \pm 0.39(9) \\
3.21 \pm 1.22 \\
0.8613 \\
\text { NS }\end{array}$ \\
\hline Oxo & $\begin{array}{l}\text { Pre } \\
\text { Post } 1 \\
\text { Post } 2 \\
\text { Post } 3 \\
\text { ANOVA }\end{array}$ & $\begin{array}{l}10 \\
10 \\
10 \\
8 \\
P \text { value } \\
\text { Significance }\end{array}$ & $\begin{array}{l}82.3 \pm 31.7 \\
49.5 \pm 19.4^{\mathrm{a}} \\
92.2 \pm 49.3 \\
90.3 \pm 28.6 \\
0.4041 \\
\text { NS }\end{array}$ & $\begin{array}{l}2.3 \pm 1.3 \\
2.7 \pm 1.7 \\
3.1 \pm 1.5 \\
2.8 \pm 1.4 \\
0.3410 \\
\text { NS }\end{array}$ & $\begin{array}{l}376 \pm 180 \\
286 \pm 102 \\
496 \pm 261 \\
488 \pm 214 \\
0.7775 \\
\text { NS }\end{array}$ & $\begin{array}{l}2.76 \pm 0.82 \\
4.25 \pm 1.28^{\mathrm{a}}(6) \\
4.31 \pm 1.07^{\mathrm{a}}(7) \\
4.31 \pm 1.38(7) \\
0.0070 \\
P<0.05\end{array}$ \\
\hline
\end{tabular}

\begin{tabular}{|c|c|c|c|c|c|c|}
\hline & Assay point & No. of pts & $C_{\max }(\mathrm{ng} / \mathrm{ml})$ & $T_{\max }(\mathrm{h})$ & $\operatorname{AUC}_{0-8 \mathrm{~h}}(\mathrm{ng} \mathrm{h} / \mathrm{ml})$ & $t_{1 / 2}^{\mathrm{a}}(\mathrm{h})$ \\
\hline FT & $\begin{array}{l}\text { Pre } \\
\text { Post } 1 \\
\text { Post } 2 \\
\text { Post } 3 \\
\text { ANOVA }\end{array}$ & $\begin{array}{l}5 \\
5 \\
5 \\
3 \\
P \text { value } \\
\text { Significance }\end{array}$ & $\begin{array}{l}3,511 \pm 870 \\
3,679 \pm 980 \\
4,602 \pm 1,370 \\
4,129 \pm 1,829 \\
0.1368 \\
\text { NS }\end{array}$ & $\begin{array}{l}1.8 \pm 1.3 \\
2.0 \pm 1.2 \\
2.6 \pm 3.0 \\
2.3 \pm 1.5 \\
0.4411 \\
\text { NS }\end{array}$ & $\begin{array}{l}21,067 \pm 6,623 \\
23,609 \pm 8,077 \\
28,264 \pm 10,135 \\
23,973 \pm 12,397 \\
0.0521 \\
\text { NS }\end{array}$ & $\begin{array}{l}9.55 \pm 5.32 \\
11.01 \pm 5.76 \\
8.44 \pm 1.74(4) \\
7.90 \pm 3.93 \\
0.7766 \\
\text { NS }\end{array}$ \\
\hline $5-\mathrm{FU}$ & $\begin{array}{l}\text { Pre } \\
\text { Post } 1 \\
\text { Post } 2 \\
\text { Post } 3 \\
\text { ANOVA }\end{array}$ & $\begin{array}{l}5 \\
5 \\
5 \\
3 \\
P \text { value } \\
\text { Significance }\end{array}$ & $\begin{array}{l}239 \pm 27 \\
199 \pm 53 \\
223 \pm 81 \\
203 \pm 73 \\
0.1999 \\
\text { NS }\end{array}$ & $\begin{array}{l}2.8 \pm 1.6 \\
2.8 \pm 1.1 \\
3.8 \pm 2.7 \\
3.3 \pm 1.2 \\
0.2212 \\
\text { NS }\end{array}$ & $\begin{array}{l}1,137 \pm 197 \\
1,008 \pm 194 \\
1,156 \pm 508 \\
940 \pm 186 \\
0.4048 \\
\text { NS }\end{array}$ & $\begin{array}{l}2.45 \pm 0.73 \\
3.38 \pm 2.32 \\
2.55 \pm 0.68(4) \\
2.74 \pm 1.21 \\
0.1006 \\
\text { NS }\end{array}$ \\
\hline CDHP & $\begin{array}{l}\text { Pre } \\
\text { Post } 1 \\
\text { Post } 2 \\
\text { Post } 3 \\
\text { ANOVA }\end{array}$ & $\begin{array}{l}5 \\
5 \\
5 \\
3 \\
P \text { value } \\
\text { Significance }\end{array}$ & $\begin{array}{l}318 \pm 122 \\
229 \pm 62 \\
411 \pm 187 \\
372 \pm 160 \\
0.9864 \\
\text { NS }\end{array}$ & $\begin{array}{l}2.0 \pm 1.2 \\
2.4 \pm 1.5 \\
2.8 \pm 2.9 \\
2.7 \pm 1.2 \\
0.4257 \\
\text { NS }\end{array}$ & $\begin{array}{l}1,332 \pm 468 \\
1,134 \pm 230 \\
1,694 \pm 673 \\
1,399 \pm 368 \\
0.7741 \\
\text { NS }\end{array}$ & $\begin{array}{l}3.34 \pm 0.89 \\
4.44 \pm 2.46 \\
2.94 \pm 0.20(4) \\
2.64 \pm 0.50 \\
0.9910 \\
\text { NS }\end{array}$ \\
\hline Oxо & $\begin{array}{l}\text { Pre } \\
\text { Post } 1 \\
\text { Post } 2 \\
\text { Post } 3 \\
\text { ANOVA }\end{array}$ & $\begin{array}{l}5 \\
5 \\
5 \\
3 \\
P \text { value } \\
\text { Significance }\end{array}$ & $\begin{array}{l}92.0 \pm 40.1 \\
48.9 \pm 12.1 \\
83.5 \pm 28.4 \\
80.2 \pm 12.9 \\
0.3839 \\
\text { NS }\end{array}$ & $\begin{array}{l}2.2 \pm 1.1 \\
2.4 \pm 1.5 \\
3.6 \pm 1.7 \\
3.3 \pm 1.2 \\
0.2923 \\
\text { NS }\end{array}$ & $\begin{array}{l}449 \pm 216 \\
289 \pm 34 \\
478 \pm 150 \\
465 \pm 87 \\
0.8354 \\
\text { NS }\end{array}$ & $\begin{array}{l}2.76 \pm 0.72 \\
5.25(2) \\
3.90 \pm 1.26(3) \\
3.17 \pm 0.95(3) \\
0.1429 \\
\text { NS }\end{array}$ \\
\hline
\end{tabular}

\section{Discussion}

The results of this study show no large change in the pharmacokinetic parameters of 5-FU after administration of S-1 due to gastrectomy, indicating that S-1 can be a useful postoperative adjuvant chemotherapy drug for gastric cancer. To the best of our knowledge, this is the first report to investigate the effect of gastrectomy on the pharmacokinetics of S-1, based on comprehensive pharmacokinetic analyses of all the components of $\mathrm{S}-1$, repeatedly in the same patients and at several time points. 
Table 3 PK parameters after administration of S-1 for total gastrectomy cases $(n=5)$

\footnotetext{
a Paired $t$ test, $P<0.05$ versus Pre

b If missing data exist, the number of patients was shown in parenthesis
}

\begin{tabular}{|c|c|c|c|c|c|c|}
\hline & Assay point & No. of pts & $C_{\max }(\mathrm{ng} / \mathrm{ml})$ & $T_{\max }(\mathrm{h})$ & $\operatorname{AUC}_{0-8 \mathrm{~h}}(\mathrm{ng} \mathrm{h} / \mathrm{ml})$ & $t_{1 / 2}^{\mathrm{b}}(\mathrm{h})$ \\
\hline FT & $\begin{array}{l}\text { Pre } \\
\text { Post } 1 \\
\text { Post } 2 \\
\text { Post } 3 \\
\text { ANOVA }\end{array}$ & $\begin{array}{l}5 \\
5 \\
5 \\
5 \\
P \text { value } \\
\text { Significance }\end{array}$ & $\begin{array}{l}2,014 \pm 744 \\
2,814 \pm 737^{\mathrm{a}} \\
3,356 \pm 1,023^{\mathrm{a}} \\
3,576 \pm 1,729^{\mathrm{a}} \\
0.0090 \\
P<0.05\end{array}$ & $\begin{array}{l}1.6 \pm 0.5 \\
1.6 \pm 1.3 \\
1.0 \pm 0.0 \\
1.4 \pm 0.5 \\
0.2770 \\
\text { NS }\end{array}$ & $\begin{array}{l}11,168 \pm 4,952 \\
15,365 \pm 5,249 \\
17,907 \pm 7,712^{\mathrm{a}} \\
20,583 \pm 10,978^{\mathrm{a}} \\
0.0101 \\
P<0.05\end{array}$ & $\begin{array}{l}8.52 \pm 4.38 \\
5.84 \pm 1.78 \\
7.04 \pm 1.79 \\
7.57 \pm 1.99 \\
0.5449 \\
\text { NS }\end{array}$ \\
\hline $5-\mathrm{FU}$ & $\begin{array}{l}\text { Pre } \\
\text { Post } 1 \\
\text { Post } 2 \\
\text { Post } 3 \\
\text { ANOVA }\end{array}$ & $\begin{array}{l}5 \\
5 \\
5 \\
5 \\
P \text { value } \\
\text { Significance }\end{array}$ & $\begin{array}{l}222 \pm 106 \\
237 \pm 127 \\
215 \pm 50 \\
189 \pm 40 \\
0.9011 \\
\text { NS }\end{array}$ & $\begin{array}{l}2.4 \pm 1.5 \\
1.6 \pm 0.5 \\
2.2 \pm 1.1 \\
2.4 \pm 0.9 \\
0.7533 \\
\text { NS }\end{array}$ & $\begin{array}{l}972 \pm 391 \\
1,016 \pm 457 \\
984 \pm 297 \\
949 \pm 268 \\
0.7157 \\
\text { NS }\end{array}$ & $\begin{array}{l}2.48 \pm 1.33 \\
2.23 \pm 0.71 \\
2.20 \pm 0.21 \\
2.50 \pm 0.41 \\
0.9608 \\
\text { NS }\end{array}$ \\
\hline CDHP & $\begin{array}{l}\text { Pre } \\
\text { Post } 1 \\
\text { Post } 2 \\
\text { Post } 3 \\
\text { ANOVA }\end{array}$ & $\begin{array}{l}5 \\
5 \\
5 \\
5 \\
P \text { value } \\
\text { Significance }\end{array}$ & $\begin{array}{l}275 \pm 127 \\
194 \pm 63 \\
335 \pm 89 \\
313 \pm 75 \\
0.9809 \\
\text { NS }\end{array}$ & $\begin{array}{l}2.4 \pm 1.5 \\
1.4 \pm 0.5 \\
2.0 \pm 1.2 \\
2.0 \pm 1.2 \\
0.4701 \\
\text { NS }\end{array}$ & $\begin{array}{l}1,088 \pm 292 \\
903 \pm 175 \\
1,372 \pm 399 \\
1,510 \pm 489 \\
0.5690 \\
\text { NS }\end{array}$ & $\begin{array}{l}3.64 \pm 1.96 \\
3.57 \pm 1.25(4) \\
3.26 \pm 0.46 \\
3.55 \pm 1.45 \\
0.8637 \\
\text { NS }\end{array}$ \\
\hline Oxo & $\begin{array}{l}\text { Pre } \\
\text { Post } 1 \\
\text { Post } 2 \\
\text { Post } 3 \\
\text { ANOVA }\end{array}$ & $\begin{array}{l}5 \\
5 \\
5 \\
5 \\
P \text { value } \\
\text { Significance }\end{array}$ & $\begin{array}{l}72.5 \pm 20.3 \\
50.0 \pm 26.5 \\
100.9 \pm 66.8 \\
96.3 \pm 35.0 \\
0.8352 \\
\text { NS }\end{array}$ & $\begin{array}{l}2.4 \pm 1.5 \\
3.0 \pm 2.0 \\
2.6 \pm 1.3 \\
2.4 \pm 1.5 \\
0.7863 \\
\text { NS }\end{array}$ & $\begin{array}{l}304 \pm 116 \\
283 \pm 149 \\
514 \pm 360 \\
502 \pm 275 \\
0.5808 \\
\text { NS }\end{array}$ & $\begin{array}{l}2.75 \pm 0.99 \\
3.75 \pm 1.12(4) \\
4.62 \pm 0.98^{\mathrm{a}}(4) \\
5.16 \pm 0.98^{\mathrm{a}}(4) \\
0.0318 \\
P<0.05\end{array}$ \\
\hline
\end{tabular}

$\mathrm{S}-1$ is an oral fluoropyrimidine containing CDHP, used instead of uracil in UFT, to enhance efficacy by more potent DPD inhibition and containing Oxo to reduce gastrointestinal toxicity. Sobrero et al. [11] classified S-1 as a DPD inhibitory fluoropyrimidine (DIF). Yamada et al. [16] reported, based on a comparison of plasma pharmacokinetics of S-1 and that of 5-FU protracted venous infusion (PVI) in the Japanese patient cohort, that the concentration of F- $\beta$-alanine, a catabolite of 5-FU, was significantly lower and plasma uracil concentrations were significantly higher in the S-1 administration group than in the 5-FU PVI group, thus clearly demonstrating the effect of DPD inhibition in metastatic gastric cancer patients.

Conducting a study of the effect of gastrectomy on pharmacokinetics of oral drug is informative guide to determine how adjuvant chemotherapy should be administered over a long period after gastrectomy. In addition, it has been reported that malabsorption of nutrients due to rapid intestinal transit and bacterial overgrowth may occur in gastrectomy patients $[1,15]$. Maehara et al. [7] studied the effects of gastric cancer surgery on the plasma pharmacokinetics of UFT, which has been widely used in Japan as adjuvant chemotherapy in patients with gastric cancer. Their results showed that the plasma pharmacokinetics of 5-FU after postoperative UFT administration were not influenced by surgery in patients undergoing total gastrectomy, while 5-FU concentration decreased in the early postoperative period in patients undergoing partial gastrectomy. The authors thus conclude that as dose increases the timing of administration should be given with careful consideration.

The only available results concerning S-1 were from a study of pharmacokinetics after a single dose of S-1 in a clinical phase I study in patients with advanced unresectable and recurrent cancer, in which a comparison was made between three patients with recurrent gastric cancer (with no stomach) and nine patients (with stomach) [2]. The study reported that gastrectomy had almost no effect on the concentration of 5-FU, and that the plasma concentration of Oxo was slightly higher in patients with recurrent gastric cancer. Limitations of the study included (1) the investigation was not conducted in the same patients, and (2) since the patients were recurrent cases, a considerable amount of time had elapsed since gastrectomy, but the numbers of days after surgery were not included in the study. Most recently, Tsuruoka et al. also reported on the effect of gastrectomy on pharmacokinetics of S-1. They concluded that the $\mathrm{AUC}_{0-8 \mathrm{~h}}$ values of 5-FU and $\mathrm{CDHP}$ after S-1 administration were similar to before surgery and that gastrectomy had almost no effect on the pharmacokinetics of S-1, however, not all components of S1 were investigated and only data from around 14 days after surgery were provided in that study [14]. Clearly, more detailed studies are necessary. With respect to the timing of measurement after surgery, especially, a 
study of pharmacokinetics at 2-4 weeks after surgery, when postoperative adjuvant chemotherapy is generally started, could provide important data to determine the optimal initial dose of postoperative S-1 adjuvant chemotherapy in the future.

The results of our study demonstrated that none of the pharmacokinetic parameters of 5-FU and CDHP after administration of S-1 on postoperative days 18 , 28 , and 42 differed significantly from those before surgery, indicating that the effect of gastrectomy on the safety and efficacy of S-1 will be small. Similar results were obtained for the subgroups of patients undergoing partial gastrectomy and total gastrectomy.

On the other hand, significant variations in $\mathrm{AUC}_{0-8} \mathrm{~h}$ and $C_{\max }$ of FT from the preoperative values were observed on several measurement days after surgery. Although no significant variations were observed in patients undergoing partial gastrectomy, patients in both groups tended to increase in FT level after surgery and that was apparent in total gastrectomy patients. Since the twice daily schedule of S-1 treatment limited the sampling over $8 \mathrm{~h}$ after drug administration, the half-life time determined for FT in this study did not correspond to the true terminal phase. The calculated apparent half-life ranged from ca. 7 to $9 \mathrm{~h}$, and which is considerably shorter than that reported by Hirata et al. [2], as ranging from 13 to $16 \mathrm{~h}$. Therefore, a part of patients who shows longer half-life time might not reach the steady state on Pre (day 4 after the start of preoperative S-1 administration) and on Post 1 (day 4 after the start of postoperative S-1 administration). The apparent increase in FT level observed on day 28 and 42 may correlate with the PK sampling schedule applied in this study.

Taken together with these results, a question may arise, why the active metabolite 5-FU did not increase with increase in the level of parent FT? Since the total body clearance of 5-FU is very large, that cannot increase in plasma level without inhibitory effect of CDHP against DPD. Consequently, the 5-FU exposure is primarily affected by concentration of CDHP rather than the elimination of parent FT. This can be clearly understood with the correlations between the $\mathrm{AUC}_{0-8 \mathrm{~h}}$ of 5-FU, FT, and CDHP as shown in Fig. 3. Actually, in spite of the large difference in $\mathrm{AUC}_{0-8 \mathrm{~h}}$ and $C_{\text {max }}$ of FT between patients with total gastrectomy and with partial gastrectomy, however 5-FU parameters were similar in those groups. Therefore, observed difference in FT before and after gastrectomy might not significantly affect 5-FU exposure, and probably less clinically meaningful.

The $\mathrm{AUC}_{0-8 \mathrm{~h}}$ and $C_{\max }$ of Oxo tended to decrease on day 18 after surgery, although not statistically significantly, functional disorder due to gastrectomy might cause defective absorption of Oxo, especially in the postoperative early stage. Interestingly, significant differences of $t_{1 / 2}$ were observed after surgery, and that was relatively apparent in the total gastrectomy patients. However for Oxo, its inter-individual variability (typically $50 \%$ or over as CV) as well as intra-individual variability are larger than that of FT, CDHP, and 5-FU. Therefore, we should pay attention to understand the result especially for half-life time of Oxo, because the data was obtained from limited number of patients.

Kinoshita et al. reported a feasibility study of S-1 in 35 resected gastric cancer patients. In that study, S-1 was administered at $80 \mathrm{mg} / \mathrm{m}^{2} /$ day for 4 weeks followed by 2 weeks of drug suspension as one course starting at 4 weeks after surgery [4]. According to that study, the planned eight courses of S-1 were administered to 17 of 35 patients $(60.7 \%)$, and the median percent of actual administration days with respect to the total number of planned administration days (28 days $\times 8$ ) was $79.0 \%$. Postoperative administration of S-1 for 1 year thus seems feasible as adjuvant chemotherapy for gastric cancer. One problem in that trial was a high incidence of patient refusal due to adverse reactions, mainly anorexia, in the first course. The authors mentioned that a delay in the start of drug administration seems necessary for adjuvant use to prevent these problems [4]. Oxо reduces gastrointestinal toxicities including not only diarrhea but also vomiting [3]. Since Oxo also
Fig. 3 Correlations between $\mathrm{AUC}_{0-8 \mathrm{~h}}$ of FT, CDHP, and 5 -FU
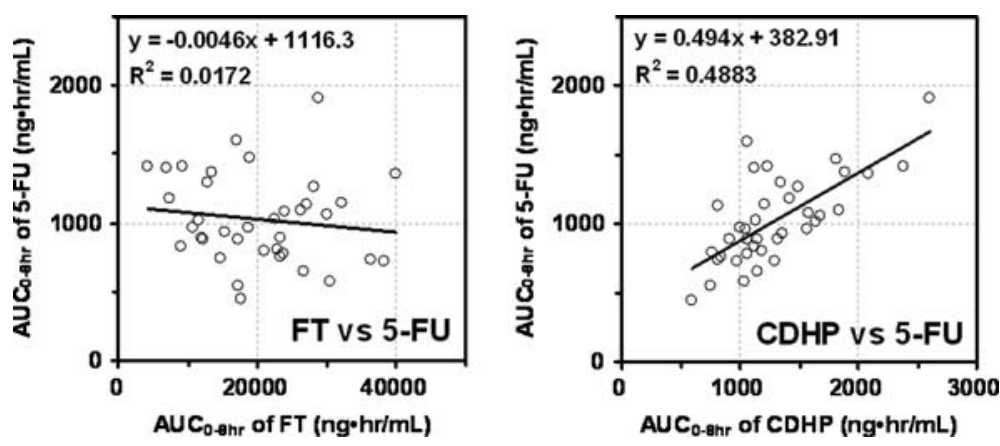
tended to decrease in the early stage (day 18), after surgery in our study, this decrease of Oxo may explain, partly, the causes of anorexia, in addition to the possibilities of surgical stress to patients and limitation of food intake due to aggressive gastrectomy [4].

In the study of 5-FU concentrations in tumors after administration of S-1, the concentration of 5-FU in a tumor around $4.5 \mathrm{~h}$ after the final administration of S-1 was $242.13 \pm 83.02 \mathrm{ng} / \mathrm{g}$. The concentration of 5 -FU in a tumor around $20 \mathrm{~h}$ after the final administration was $91.71 \pm 37.03 \mathrm{ng} / \mathrm{g}$. The mean ratio of 5-FU concentrations in tumors/normal tissue was 8.55 , and the mean ratio of 5-FU concentrations in tissue/plasma was 14.55 , indicating favorable retention in tumors over a long time period. It has been shown that CDHP inhibits DPD in the liver to maintain stable 5-FU concentrations and also enhances tumor selectivity due to inhibition of DPD in tumors [13], findings which are considered to be supported by the results of this study.

In conclusion, this study clarifies that gastrectomy does not affect the plasma pharmacokinetics of 5-FU after postoperative S-1 administration, regardless of partial or total gastrectomy, and that a stable 5-FU concentration can be maintained in patients undergoing resection of gastric cancer, although pharmacokinetic parameters of Oxo slightly changed after surgery. Based on these results, sufficient efficacy of S-1 for advanced gastric cancer is expected in adjuvant chemotherapy. A randomized controlled trial (ACTS-GC study) has been undertaken to compare surgery alone versus $\mathrm{S}-1$, administration for 1 year according to the same schedule as that employed in this study, in patients with stage II or III gastric cancer who received curative resection. So far, 1,059 patients have been registered and a follow-up investigation is currently underway. If a significant survival benefit of S-1 is shown by that trial, this could establish the standard adjuvant treatment for curatively resected gastric cancer.

Acknowledgments The authors are indebted to Prof. J. Patrick Barron of the International Medical Communications Center of Tokyo Medical University for his review of this manuscript. We thank also Dr. Ken-ichiro Yoshida and Dr. Sekio Nagayama, $\mathrm{Ph} . \mathrm{D}$. for helpful discussion with pharmacokinetic analysis and critical reading of this manuscript.

\section{References}

1. Armbrecht U, Lundell L, Lindstedt G, Stockbruegger RW (1988) Causes of malabsorption after total gastrectomy with Roux-en-Y reconstruction. Acta Chir Scand 154:37-41

2. Hirata K, Horikoshi N, Aiba K, Okazaki M, Denno R, Sasaki K, Nakano Y, Ishizuka H, Yamada Y, Uno S, Taguchi
T, Shirasaka T (1999) Pharmacokinetic study of S-1, a novel oral fluorouracil antitumor drug. Clin Cancer Res 5:20002005

3. Kato T, Shimamoto Y, Uchida J, Ohshimo H, Abe M, Shirasaka T, Fukushima M (2001) Possible regulation of 5-fluorouracil-induced neuro- and oral toxicities by two biochemical modulators consisting of S-1, a new oral formulation of 5-fluorouracil. Anticancer Res 21:1705-1712

4. Kinoshita T, Nashimoto A, Yamamura Y, Okamura T, Sasako M, Sakamoto J, Kojima H, Hiratsuka M, Arai K, Sairenji M, Fukushima N, Kimura H, Nakajima T (2004) Feasibility study of adjuvant chemotherapy with S-1 (TS-1; tegafur, gimeracil, oteracil potassium) for gastric cancer. Gastric Cancer 7:104-109

5. Koizumi W, Kurihara M, Nakano S, Hasegawa K (2000) Phase II study of S-1, a novel oral derivative of 5-fluorouracil, in advanced gastric cancer. For the S-1 Cooperative Gastric Cancer Study Group. Oncology 58:191-197

6. Maehara Y (2003) S-1 in gastric cancer: a comprehensive review. Gastric Cancer 6(Suppl 1):2-8

7. Maehara Y, Takeuchi H, Oshiro T, Takahashi I, Inutsuka S, Baba H, Kohnoe S, Sugimachi K (1994) Effect of gastrectomy on the pharmacokinetics of tegafur, uracil, and 5-fluorouracil after oral administration of a 1:4 tegafur and uracil combination. Cancer Chemother Pharmacol 33:445-449

8. Matsushima E, Yoshida K, Kitamura R, Yoshida K (1997) Determination of S-1 (combined drug of tegafur, 5-chloro2,4-dihydroxypyridine and potassium oxonate) and 5-fluorouracil in human plasma and urine using high-performance liquid chromatography and gas chromatography-negative ion chemical ionization mass spectrometry. J Chromatogr B Biomed Sci Appl 691:95-104

9. Sakata Y, Ohtsu A, Horikoshi N, Sugimachi K, Mitachi Y, Taguchi T (1998) Late phase II study of novel oral fluoropyrimidine anticancer drug S-1 (1 M tegafur- $0.4 \mathrm{M}$ gimestat- $1 \mathrm{M}$ otastat potassium) in advanced gastric cancer patients. Eur J Cancer 34:1715-1720

10. Shirasaka T, Shimamato Y, Ohshimo H, Yamaguchi M, Kato T, Yonekura K, Fukushima M (1996) Development of a novel form of an oral 5-fluorouracil derivative (S-1) directed to the potentiation of the tumor selective cytotoxicity of 5-fluorouracil by two biochemical modulators. Anticancer Drugs 7:548-557

11. Sobrero A, Kerr D, Glimelius B, Van Cutsem E, Milano G, Pritchard DM, Rougier P, Aapro M (2000) New directions in the treatment of colorectal cancer: a look to the future. Eur J Cancer 36:559-566

12. Sugimachi K, Maehara Y, Horikoshi N, Shimada Y, Sakata Y, Mitachi Y, Taguchi T (1999) An early phase II study of oral S-1, a newly developed 5-fluorouracil derivative for advanced and recurrent gastrointestinal cancers. The S-1 Gastrointestinal Cancer Study Group. Oncology 57:202-210

13. Takechi T, Fujioka A, Matsushima E, Fukushima M (2002) Enhancement of the antitumour activity of 5-fluorouracil (5-FU) by inhibiting dihydropyrimidine dehydrogenase activity (DPD) using 5-chloro-2,4-dihydroxypyridine (CDHP) in human tumour cells. Eur J Cancer 38:1271-1277

14. Tsuruoka Y, Kamano T, Kitajima M, Kawai K, Watabe S, Ochiai T, Sakamoto K, Shirasaka T (2006) Effect of gastrectomy on the pharmacokinetics of 5-fluorouracil and gimeracil after oral administration of S-1. Anticancer Drugs 17:393-399

15. Walther B, Clementsson C, Vallgren S, Ihse I, Akesson B (1989) Fat malabsorption in patients before and after total gastrectomy, studied by the triolein breath test. Scand J Gastroenterol 24:309-314 
16. Yamada Y, Hamaguchi T, Goto M, Muro K, Matsumura Y, Shimada Y, Shirao K, Nagayama S (2003) Plasma concentrations of 5-fluorouracil and F-beta-alanine following oral administration of S-1, a dihydropyrimidine dehydrogenase inhibitory fluoropyrimidine, as compared with protracted venous infusion of 5-fluorouracil. Br J Cancer 89:816-820
17. Yoshisue K, Masuda H, Matsushima E, Ikeda K, Nagayama S, Kawaguchi Y (2000) Tissue distribution and biotransformation of potassium oxonate after oral administration of a novel antitumor agent (drug combination of tegafur, 5-chloro-2,4dihydroxypyridine, and potassium oxonate) to rats. Drug Metab Dispos 28:1162-1167 